\title{
Distribuição e abundância de espécies arbóreas em cerradões no Pantanal, Estado do Mato Grosso do Sul, Brasil ${ }^{1}$
}

\author{
SUZANA MARIA SALIS ${ }^{2,5}$, MARCO ANTONIO ASSIS ${ }^{3}$, SANDRA MARA ARAÚJO CRISPIM² e \\ JOSÉ CARLOS CASAGRANDE ${ }^{4}$
}

(recebido: 19 de maio de 2005; aceito: 13 de julho de 2006)

\begin{abstract}
Distribution and abundance of tree species of savanna woodland in Pantanal wetlands, Mato Grosso do Sul State, Brazil). The woodland savannas occupy non-flooding areas in the Pantanal wetlands and are an important resource for regional economy. Even though, wood from woodland savannas are cut and used for fences, pens, and sheds in the farm, there are not much information from woodland savannas regarding sustainable uses and conservation. This study investigated the abundance, the distribution of species and correlations with soil fertility in six areas of woodland savanna ("cerradão") in Southern Pantanal wetlands. The survey was accomplished by means of 30 point-centred quarters in each area, totalling 120 trees sampled with the circumference at breast height $(\mathrm{CBH}) \geq 15 \mathrm{~cm}$. The association between floristic composition, abundance of species and soil fertility were determined by the principal components analysis (PCA). Savanna forests are very heterogeneous, presenting different levels of soil fertility as well as vegetation structure and composition. Two of them were clustered according to soil fertility and vegetation structure, they both presented large stands of the tree Qualea grandiflora Mart., species that seems to prefer soil with larger phosphorous quantity. Two other areas of savanna forests showed similar floristic composition, despite being in areas where the soil presented different levels of fertility, pointing out the human disturbance.
\end{abstract}

Key words - phosphorus, principal components analysis, savanna, soil

RESUMO - (Distribuição e abundância de espécies arbóreas em cerradões no Pantanal, Estado do Mato Grosso do Sul, Brasil). Os cerradões no Pantanal ocorrem em áreas não inundáveis da planície e são importantes para a economia regional. Das áreas de cerradão são retiradas madeiras para construção de cercas, currais e galpões. Apesar da grande importância dos recursos vegetais do cerradão, existem poucas informações para embasar sua conservação e uso sustentável. Este trabalho teve como objetivos estudar a abundância, a distribuição das espécies arbóreas e correlações com a fertilidade do solo em áreas de cerradão (savana florestada) do Pantanal Sul Mato-grossense. Foram estudadas seis áreas de cerradão na sub-região da Nhecolândia, por meio de 30 pontos quadrantes, totalizando 120 árvores amostradas, com circunferência a altura do peito (CAP) $\geq 15$ cm, em cada área. As comparações florísticas, de abundância das espécies e de fertilidade do solo, foram efetuadas por análises de componentes principais (PCA). As áreas mostraram-se heterogêneas, apresentando diferentes níveis de fertilidade do solo, estrutura e composição da vegetação. Dois cerradões foram agrupados em termos de fertilidade do solo e de estrutura da vegetação, apresentando muitas árvores de Qualea grandiflora Mart., espécie que ocorreu associada a solos com maiores teores de fósforo. Outros dois cerradões apresentaram composição florística mais semelhante que os demais, apesar de ocorrerem em solos com diferentes níveis de fertilidade, indicando perturbação antrópica.

Palavras-chave - análise de componentes principais, cerrado, fósforo, solo

\section{Introdução}

O Pantanal, planície inundável com cerca de 140.000 km², vem sendo ocupado há mais de 200 anos

1. Parte da tese de doutorado de Suzana Maria Salis, Programa de Biologia Vegetal da Universidade Estadual Paulista, Rio Claro, São Paulo, Brasil.

2. Embrapa Pantanal, Caixa Postal 109, 79320-900 Corumbá, Mato Grosso do Sul, Brasil.

3. Universidade Estadual Paulista, Instituto de Biociências, Departamento de Botânica, Caixa Postal 199, 13506-900 Rio Claro, São Paulo, Brasil.

4. Universidade Federal de São Carlos, Centro de Ciências Agrárias, Departamento de Recursos Naturais e Proteção Ambiental, Caixa Postal 153, 13600-970 Araras, São Paulo, Brasil.

5. Autora para correspondência: smsalis@cpap.embrapa.br para a criação extensiva de gado bovino. Esta atividade econômica utiliza os recursos naturais regionais: a pastagem nativa para a alimentação do rebanho e a madeira das árvores nativas para a construção de cercas, currais e galpões. Apesar da grande importância desses recursos para a região, existem poucas informações para embasar sua conservação e uso sustentável.

As primeiras informações sobre a flora pantaneira foram colhidas no final do século XIX por naturalistas europeus, como Moore (1895) e Malme (1905), que trataram as espécies de algumas famílias (Leguminosae e Vochysiaceae). Posteriormente, Veloso (1947) relacionou os tipos de vegetação com a inundação e a sua composição de espécies. Pott et al. $(1986,1997)$ e 
Guarim Neto (1991) elaboraram listagens das espécies ocorrentes no Pantanal e Damasceno Júnior et al. (1999) estudaram a composição florística dos capões do Pantanal do Abobral, Município de Corumbá, Estado do Mato Grosso do Sul.

Quanto aos aspectos fitossociológicos, os trabalhos pioneiros no Pantanal foram realizados por Prance \& Schaller (1982), Ratter et al. (1988b), Nascimento \& Cunha (1989) e Cunha (1990) em florestas, cerrados e cerradões. Posteriormente, Dubs (1992), Soares (1997), Salis et al. (1999) e Salis (2000) realizaram estudos de estrutura em cerradão e florestas no Pantanal da Nhecolândia no Estado do Mato Grosso do Sul e Cunha \& Junk (1999) no Pantanal de Poconé, no Estado do Mato Grosso.

Em relação à distribuição das espécies características das áreas de domínio do cerrado, que também integram o “complexo vegetacional” do Pantanal, tem-se uma flora característica e diferenciada dos biomas adjacentes, embora muitas fisionomias do cerrado compartilhem espécies com outros biomas (Prado \& Gibbs 1993, Oliveira Filho \& Ratter 1995). Espécies de florestas decíduas e semidecíduas ocorrem em manchas de solo de média a alta fertilidade nas fisionomias do cerrado e tendem a se distribuir principalmente ao longo de um arco nordeste-sudoeste que conecta as caatingas às fronteiras do chaco (Oliveira Filho \& Ratter 1995).

Em trabalhos mais recentes conduzidos por Ratter et al. (1996, 2003) e Castro et al. (1999), foram estudados os padrões de distribuição da vegetação dos cerrados brasileiros por comparações de um grande número de levantamentos florísticos usando técnicas de análise multivariada. Ratter et al. (2003) no estudo comparativo entre 376 áreas de cerrado, observaram um marcante padrão geográfico na distribuição da flora, reconhecendo seis grupos florísticos diferentes: Sudeste, composto pelo cerrados do Estado de São Paulo, Paraná e Sul de Minas Gerais; Centro-Sudoeste (cerrados do Distrito Federal e de Minas Gerais); Norte-Nordeste (Bahia, Ceará, Norte de Minas Gerais, Maranhão, Piauí e porção Leste de Tocantins); Centro-Oeste (Mato Grosso, Mato Grosso do Sul, Goiás, porção Oeste de Tocantins e Sul do Pará); mesotrófico-oeste (cerrados de vários estados, mas principalmente de Rondônia e de Mato Grosso do Sul) e um grupo de áreas disjuntas, composto pelas savanas amazônicas.

Este estudo teve como objetivos avaliar e comparar a abundância e a distribuição das espécies arbóreas em seis áreas de cerradão (savana florestada) no Pantanal da Nhecolândia, Mato Grosso do Sul, relacionando-as com a fertilidade do solo, visando reconhecer os padrões de distribuição das espécies.

\section{Material e métodos}

Áreas de estudo - As seis áreas de cerradão estudadas estão situadas no Pantanal da Nhecolândia, nos municípios de Corumbá e Aquidauana (figura 1), segundo a subdivisão de Hamilton et al. (1996), que se caracteriza por numerosas lagoas (baías) separadas por paleodiques aluviais denominados regionalmente como cordilheiras, que são cobertos por mata semidecídua, cerradão ou cerrado (tabelas 1-2; Ratter et al. 1988b). A primeira área de cerradão, denominada Caron (1900' S e $56^{\circ} 04^{\prime}$ W), está situada na fazenda Campo Alto e apresenta 26 ha (tabela 1). A segunda, Nhumirim (1859' S e 56 $56^{\circ} 38^{\prime} \mathrm{W}$ ), tem 10 ha e está na fazenda Nhumirim de propriedade da Embrapa Pantanal. A terceira e a quarta áreas, denominadas,

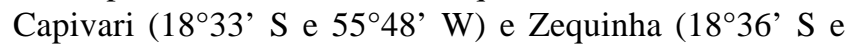
5548’ W), estão situadas na fazenda Rancharia, com 16 ha e 8 ha, respectivamente. A quinta área de estudo, Imaculada ( $18^{\circ} 52^{\prime}$ S e $55^{\circ} 51^{\prime}$ W), está na fazenda Imaculada (14 ha) e a sexta, Rio Negro (19³0' S e 56 $16^{\circ}$ ' W), localiza-se na fazenda Rio Negro (30 ha).

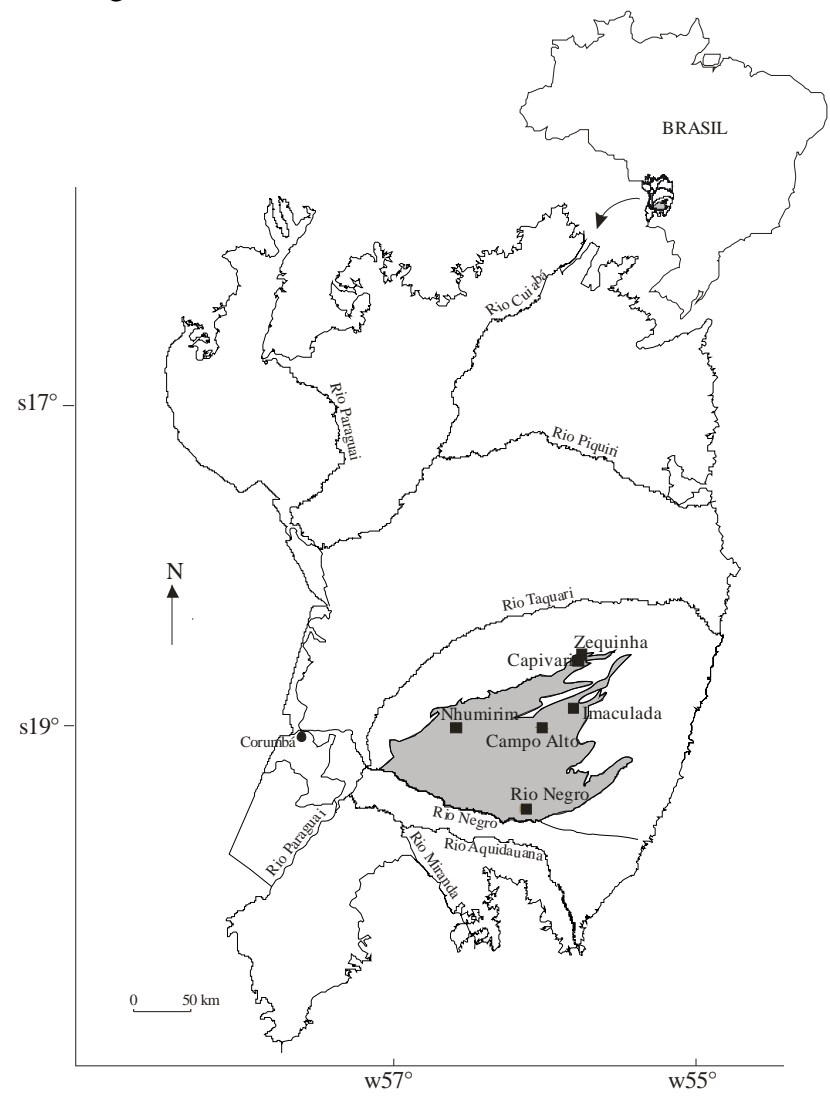

Figura 1. Localização das áreas estudadas (₫) na sub-região da Nhecolândia (área em cinza, de acordo com Hamilton et al. 1996) no Pantanal do Brasil.

Figure 1. Study sites ( $\mathbf{\square})$ in Nhecolandia region (gray area, according Hamilton et al. 1996), in Pantanal wetland, Brazil. 
Tabela 1. Variáveis da comunidade arbórea, tamanho da área e diversidade dos seis cerradões amostrados no Pantanal da Nhecolândia, Brasil. (Área (ha); N spp. = número de espécies; $\mathrm{N}$ ind. eutr. = número de indivíduos das espécies indicadoras de solo eutrófico e N spp. eutr. = número de espécies indicadoras de solo eutrófico; DT = densidade total de árvores (indivíduos ha-1 ${ }^{-1}$; $H^{\prime}$ = diversidade de Shannon e $J$ = eqüidade, usando $H^{\prime}$ ).

Table 1. Variables of tree community, size area and diversity of six savanna forests in "Pantanal da Nhecolândia” wetlands, Brazil. (Area (ha); N spp. = number of species; $\mathrm{N}$ ind. eutr. = number of individuals of eutrophic soil indicator species and $\mathrm{N}$ spp. eutr. = number of eutrophic soil indicator species; DT = total density (individuals ha ${ }^{-1}$ ); $H^{\prime}=$ Shannon diversity, and $J=$ evenness, using $\left.H^{\prime}\right)$.

\begin{tabular}{|c|c|c|c|c|c|c|c|c|}
\hline Cerradão & Área & N spp. & $\mathrm{N}$ ind. eutr. & N spp. eutr. & Espécies mais abundantes* & DT & $H^{\prime}$ & $J$ \\
\hline Caron & 26 & 38 & 36 & 11 & $\begin{array}{l}\text { Protium heptaphyllum } \\
\text { Astronium fraxinifolium } \\
\text { Cecropia pachystachya }\end{array}$ & 833 & 3,05 & 0,84 \\
\hline Nhumirim & 10 & 43 & 19 & 08 & $\begin{array}{l}\text { Alibertia sessilis } \\
\text { Protium heptaphyllum } \\
\text { Zanthoxylum rigidum }\end{array}$ & 706 & 3,36 & 0,89 \\
\hline Capivari & 16 & 30 & 31 & 07 & $\begin{array}{l}\text { Qualea grandiflora } \\
\text { Caryocar brasiliense } \\
\text { Lafoensia pacari }\end{array}$ & 581 & 3,09 & 0,91 \\
\hline Zequinha & 8 & 37 & 59 & 12 & $\begin{array}{l}\text { Magonia pubescens } \\
\text { Qualea grandiflora }\end{array}$ & 699 & 2,90 & 0,80 \\
\hline Imaculada & 14 & 34 & 33 & 08 & $\begin{array}{l}\text { Licania minutiflora } \\
\text { Lafoensia pacari } \\
\text { Astronium fraxinifolium }\end{array}$ & 570 & 3,22 & 0,91 \\
\hline Rio Negro & 30 & 27 & 50 & 10 & $\begin{array}{l}\text { Protium heptaphyllum } \\
\text { Diptychandra aurantiaca } \\
\text { Magonia pubescens }\end{array}$ & 783 & 2,91 & 0,88 \\
\hline
\end{tabular}

*espécies, que, somadas representam entre 30\% a 40\% dos indivíduos amostrados na área.

Todas as áreas estudadas apresentaram sinais de passagem de fogo. Pelo histórico levantado e pelo acompanhamento da vegetação nas áreas de estudo nos últimos anos, notou-se que Rio Negro e Nhumirim sofreram queimadas ocasionais. As áreas Caron, Capivari e Zequinha estiveram mais vulneráveis, queimando a cada dois ou três anos e Imaculada apresentou queimadas anuais. Exceto as áreas Nhumirim e Rio Negro, nas demais, a vegetação de cerradão estava sujeita ao pastejo extensivo pelo gado. No cerradão da fazenda Imaculada foram observadas árvores serradas rente ao chão, indicando recente retirada de madeira. $\mathrm{Na}$ área denominada Caron, segundo informações do proprietário, foram retiradas, há algum tempo, madeiras para palanques de cerca.

O clima da região é do tipo Aw, segundo o sistema de Köppen, tropical megatérmico, com a temperatura média do mês mais frio superior a $18^{\circ} \mathrm{C}$, com inverno seco e chuvas no verão. As médias anuais de precipitação e temperatura, no período de 1977-1995, foram 1.182,7 mm e 25,5 ${ }^{\circ} \mathrm{C}$, respectivamente (Soriano 1999). A maior precipitação média ocorre em janeiro, com 216,8 mm, e a menor, em julho, com 19,7 mm (Soriano 2002). As temperaturas máximas absolutas podem chegar a $40{ }^{\circ} \mathrm{C}$ nos meses de outubro a janeiro e as mínimas, próximas a $0{ }^{\circ} \mathrm{C}$, em junho e julho (Embrapa 1997). A região pode apresentar deficiência hídrica anual superior a $300 \mathrm{~mm}$, principalmente nos meses de agosto a outubro (Soriano 1999).

O relevo é plano, com altitude aproximada de $90 \mathrm{~m}$ acima do nível do mar (Ratter et al. 1988b). Os solos pertencem, predominantemente, ao grupo Espodossolo Ferrocárbico Hidromórfico arênico (Embrapa 1999) que, em condições naturais, geralmente apresentam grandes restrições de fertilidade para manejo agro-pastoril intensivo (Cunha 1985). Com relação à textura dos solos das cordilheiras do Pantanal da Nhecolândia, Cunha $(1980,1981)$ e Santos et al. (1997) verificaram que estes são uniformes, apresentando altas percentagens de areia e baixos teores de argila mineral (2\% a $5 \%$ ).

Procedimento de campo e análise dos dados - Os levantamentos da vegetação foram realizados de março a maio de 1996 (Caron, Nhumirim, Capivari e Zequinha), e de maio a junho de 2000 (Imaculada e Rio Negro). As amostragens foram feitas pelo método de quadrantes centrados (Brower \& Zar 1984), tomando-se dois conjuntos de 15 pontos, dispostos com distância fixa de $15 \mathrm{~m}$ entre pontos, a partir de aproximadamente $10 \mathrm{~m}$ da borda da cordilheira com cerradão, 
totalizando 30 pontos e 120 indivíduos amostrados em cada área. Foram amostradas árvores com CAP (circunferência à altura do peito) igual ou superior a $15 \mathrm{~cm}$, anotando-se a altura total estimada. As plantas com caules múltiplos tiveram todos os perímetros, à altura do peito, anotados. Os indivíduos amostrados foram coletados e o material botânico foi depositado no herbário da Embrapa Pantanal (CPAP), com algumas duplicatas incluídas no herbário da Universidade Estadual Paulista, em Rio Claro (HRCB). A identificação foi realizada com auxílio de bibliografia especializada, por comparação com material dos herbários CPAP e UEC (Universidade Estadual de Campinas), e consulta a especialistas.

A coleta de solos para análise da fertilidade foi realizada com o auxílio de uma sonda, em novembro de 2002. Em cada área de estudo foi coletada uma amostra composta por 15 subamostras de solo coletadas aleatoriamente na profundidade de 0 a $20 \mathrm{~cm}$. As análises químicas foram realizadas no Laboratório de Análise Química de Solo e Planta do Centro de Ciências Agrárias da Universidade Federal de São Carlos, Campus de Araras, conforme metodologia descrita por Raij et al. (1987) - pH, matéria orgânica (MO), alumínio (Al), hidrogênio mais alumínio $(\mathrm{H}+\mathrm{Al})$, cálcio $(\mathrm{Ca})$, magnésio $(\mathrm{Mg})$, potássio $(\mathrm{K})$, fósforo $(\mathrm{P})$, enxofre $(\mathrm{S})$, boro $(\mathrm{B})$, cobre $(\mathrm{Cu})$, ferro $(\mathrm{Fe})$, manganês $(\mathrm{Mn})$ e zinco $(\mathrm{Zn})$. Foram calculadas: as soma de bases (SB), a capacidade troca catiônica (CTC), a saturação por bases (V) e a saturação por alumínio (m). Onde V é um indicador de fertilidade do solo, segundo os preceitos agronômicos (sensu Reatto et al. 1998).

As comparações florísticas, de abundância das espécies e de características químicas do solo entre as áreas de estudo foram efetuadas por análise de componentes principais (PCA), utilizando-se o programa PC-ORD for Windows versão 4.14 (McCune \& Mefford 1999). Na comparação florística foi utilizada uma matriz de presença e ausência com 49 espécies, após exclusão das que ocorreram em apenas uma das áreas $(n=34)$ e também das que ocorreram em todas as áreas $(n=3)$, por não contribuírem para a avaliação da similaridade (Kent \& Coker 1999). Para a comparação da abundância das espécies, utilizou-se uma matriz com 36 espécies, considerando-se apenas as espécies com mais de dois indivíduos, excluídas também aquelas que ocorreram em uma única área.

Na comparação das características do solo, fez-se a análise de PCA com 18 variáveis. Entretanto, para a representação gráfica optou-se por apresentar somente as oito variáveis com maiores valores de vetor no primeiro eixo e no segundo eixo: $\mathrm{Ca}, \mathrm{Mg}, \mathrm{P}, \mathrm{MO}, \mathrm{H}+\mathrm{Al}, \mathrm{SB}$ (= $\mathrm{Ca}+\mathrm{Mg}+$ $\mathrm{K}$ ), meV.

Para cada área foi calculado o número total de indivíduos de espécies indicadoras de solos eutróficos, de acordo com Ratter et al. (1988b, 1996), o índice de diversidade de Shannon $\left(H^{\prime}\right)$, a eqüidade $(J)$ usando $H^{\prime}$, a densidade total, a área basal e a distância média entre árvores pelo programa Fitopac (Shepherd 1988).

\section{Resultados}

Vegetação - Os dados registrados para as seis áreas apontam para uma elevada heterogeneidade entre os cerradões estudados, pois os valores são bastante variáveis tanto em relação aos descritores da composição florística, tais como o número de espécies (27 a 43), a diversidade $(2,90$ a 3,36$)$ e a eqüidade $(0,80$ a 0,91 ), quanto aos descritores estruturais, como densidade total (570 a 1.157 indivíduos ha-1) e número de indivíduos por espécie (tabelas 1-2).

Considerando-se as seis áreas de estudo conjuntamente, foram encontradas 86 espécies, distribuídas em 74 gêneros e 37 famílias dispostas na tabela 2 em ordem alfabética de acordo com APG II (2003). Desse total, somente três espécies, Astronium fraxinifolium, Protium heptaphyllum e Tabebuia aurea, foram registradas para todas as áreas. O cerradão do Rio Negro, com dossel mais fechado, foi o que apresentou menor riqueza de espécies (27). Já na área da fazenda Nhumirim, um cerradão mais aberto, com alta densidade de indivíduos de pequeno porte, como Alibertia sessilis e Chomelia obtusa, apresentou o maior número de espécies (43), ocorrendo desde espécies típicas de locais abertos até aquelas características de vegetação mais densa. As áreas Caron, Capivari, Imaculada e Zequinha apresentaram número de espécies variando entre 30 e 38, com predomínio de espécies comuns em cerradão no Pantanal.

As duas PCA com dados das espécies (presença/ ausência e abundância) apresentaram resultados semelhantes. Na PCA da composição florística (figura 2), o primeiro eixo apresentou 32\% de variância (autovalor de 15,7) e o segundo eixo, 26\% (autovalor de 12,8 ) e na PCA da estrutura (figura 3), o primeiro eixo explicou $33 \%$ da variância (autovalor de 11,9 ) e o segundo eixo, 23\% (autovalor de 8,1). O cerradão Rio Negro se distinguiu, floristicamente, pela ausência de Caryocar brasiliense, Luehea paniculata, Mouriri elliptica e Qualea spp. (tabela 1) e, estruturalmente, por apresentar muitos indivíduos de Diptychandra aurantiaca. As áreas Capivari, Zequinha e Imaculada tenderam a formar um grupo nas análises de vegetação, sendo agrupadas estruturalmente, principalmente pela ocorrência de muitos indivíduos de Qualea grandiflora, Lafoensia pacari e Caryocar brasiliense.

Os cerradões Caron e Nhumirim foram os mais similares, tanto na composição florística, como na estrutura (abundância das espécies), considerando-se o primeiro eixo nas duas análises (figuras 2-3), apesar de 
Tabela 2. Espécies amostradas nos seis cerradões do Pantanal da Nhecolândia, Brasil, com respectivos nomes comuns e números de indivíduos amostrados em cada área ( 1 = Caron; 2 = Nhumirim; 3 = Capivari; 4 = Zequinha; 5 = Imaculada; 6 = Rio Negro).

Table 2. Species sampled in six savanna forests of "Pantanal da Nhecolândia” wetland, Brazil, with common names and number of trees in the studied areas ( 1 = Caron; 2 = Nhumirim; 3 = Capivari; 4 = Zequinha; 5 = Imaculada; 6 = Rio Negro).

\begin{tabular}{|c|c|c|c|c|c|c|c|}
\hline \multirow[t]{2}{*}{ Família/ Espécie } & \multirow[t]{2}{*}{ Nome popular } & \multicolumn{6}{|c|}{ Áreas amostradas } \\
\hline & & 1 & 2 & 3 & 4 & 5 & 6 \\
\hline \multicolumn{8}{|l|}{ ANACARDIACEAE } \\
\hline Astronium fraxinifolium Schott ex Spreng.* & gonçalo & 15 & 2 & 8 & 5 & 11 & 2 \\
\hline Myracrodruon urundeuva Allemão* & aroeira & 2 & & & & & \\
\hline \multicolumn{8}{|l|}{ ANNONACEAE } \\
\hline Duguetia furfuracea (A. St.-Hil.) Saff. & ata-brava & & 2 & & 1 & & \\
\hline Xylopia aromatica (Lam.) Mart. & pindaíba & & & & 3 & 3 & \\
\hline \multicolumn{8}{|l|}{ APOCYNACEAE } \\
\hline Aspidosperma subincanum Mart.* & peroba & & & & 1 & & \\
\hline A. tomentosum Mart. & peroba-do-campo & & & 3 & & & \\
\hline Hancornia speciosa Gomes & mangaba & & 2 & & & & \\
\hline \multicolumn{8}{|l|}{ ARECACEAE } \\
\hline Acrocomia aculeata (Jacq.) Lodd. ex Mart.* & bocaiúva & 1 & & & 3 & 3 & 2 \\
\hline Attalea phalerata Mart. ex Spreng.* & acuri & 2 & 7 & & 1 & & 8 \\
\hline \multicolumn{8}{|l|}{ BIGNONIACEAE } \\
\hline Tabebuia aurea (Manso) Benth. \& Hook. f. ex S. Moore & paratudo & 3 & 2 & 4 & 3 & 7 & 1 \\
\hline T. impetiginosa (Mart. ex DC.) Standl.* & piúva-da-mata & 2 & 2 & & 1 & & 5 \\
\hline T. ochracea (Cham.) Standl. & piúva-cascuda & 1 & 3 & 1 & & 5 & \\
\hline T. roseoalba (Ridl.) Sandwith* & piuxinga & 3 & 1 & & & & 1 \\
\hline \multicolumn{8}{|l|}{ BURSERACEAE } \\
\hline Protium heptaphyllum (Aubl.) March. & almecega & 27 & 12 & 4 & 1 & 2 & 18 \\
\hline \multicolumn{8}{|l|}{ CACTACEAE } \\
\hline Cereus peruvianus (L.) J. S. Muell. & urumbeba & 1 & 3 & & & & \\
\hline \multicolumn{8}{|l|}{ CARYOCARACEAE } \\
\hline Caryocar brasiliense Cambess. & pequi & 3 & 1 & 11 & 3 & 5 & \\
\hline \multicolumn{8}{|l|}{ CHRYSOBALANACEAE } \\
\hline Couepia grandiflora (Mart. \& Zucc.) Benth. ex Hook. f. & genciana & 2 & 1 & & & & \\
\hline Licania minutiflora (Sagot) Fritsch & cedro-d’água & & 1 & & & 9 & 10 \\
\hline L. octandra (Hoffm. ex Roem. \& Schult.) Kuntze & roxinho & 1 & & & 2 & 2 & \\
\hline Licania sp. & & & & & & 5 & \\
\hline \multicolumn{8}{|l|}{ COMBRETACEAE } \\
\hline Buchenavia tomentosa Eichler* & tarumarana & & 3 & 2 & 2 & 4 & \\
\hline Terminalia argentea (Cambess.) Mart.* & capitão & & & 9 & 2 & 4 & 10 \\
\hline \multicolumn{8}{|l|}{ CONNARACEAE } \\
\hline Rourea induta Planch. & conta & & & 3 & & & \\
\hline \multicolumn{8}{|l|}{ DILLENIACEAE } \\
\hline Curatella americana L. & lixeira & 3 & 2 & & 3 & 3 & \\
\hline \multicolumn{8}{|l|}{ EBENACEAE } \\
\hline Diospyros hispida A. DC. & fruta-de-boi & & 1 & 3 & & & \\
\hline \multicolumn{8}{|l|}{ ERYTHROXYLACEAE } \\
\hline Erythroxylum suberosum A. St.-Hil. & sombra-de-touro & & & 1 & & & \\
\hline \multicolumn{8}{|l|}{ EUPHORBIACEAE } \\
\hline Alchornea schomburgkii Klotzsch & uva-brava & & 1 & & & & \\
\hline Sapium haematospermum Müll. Arg. & leiteira & 1 & 2 & & & & \\
\hline \multicolumn{8}{|l|}{ FABACEAE } \\
\hline Acosmium dasycarpum (Vogel) Yakovlev & cascudinho & & & 1 & & & \\
\hline
\end{tabular}


continuação

Família/ Espécie

Nome popular

\begin{tabular}{llllll}
\multicolumn{5}{c}{ Áreas } & amostradas \\
\hline 1 & 2 & 3 & 4 & 5 & 6
\end{tabular}

Anadenanthera colubrina (Vell.) Brenan var. cebil (Griseb.)

angico

1

Altschul*

Andira cujabensis Benth.

Bauhinia rufa (Bong.) Steud.

Bowdichia virgilioides Kunth

Calliandra parvifolia Benth.*

Copaifera martii Hayne

Dimorphandra mollis Benth.

Dipteryx alata Vogel*

Diptychandra aurantiaca Tul.

Hymenaea stigonocarpa Mart. ex Hayne

Machaerium acutifolium Vogel

Plathymenia reticulata Benth.

Sclerolobium aureum (Tul.) Baill.

Swartzia jorori Harms

Stryphnodendron obovatum Benth.

Vatairea macrocarpa (Benth.) Ducke

LAMIACEAE

Vitex cymosa Bertero ex Spreng.

LAURACEAE

Ocotea diospyrifolia (Meisn.) Mez

LOGANIACEAE

Strychnos pseudoquina A. St.-Hil.

LYTHRACEAE

Lafoensia pacari A. St.-Hil.

MALPIGHIACEAE

Byrsonima coccolobaefolia Kunth

B. orbignyana A. Juss.

MALVACEAE

Eriotheca gracilipes (K. Schum.) A. Robyns

Guazuma ulmifolia Lam.*

Luehea paniculata Mart.*

Pseudobombax longiflorum (Mart. \& Zucc.) A. Robyns

Sterculia apetala (Jacq.) H. Karst.*

MELASTOMATACEAE

Mouriri elliptica Mart.

MELIACEAE

Trichilia elegans A. Juss.

MYRTACEAE

Eugenia aurata O. Berg.

Gomidesia palustris (DC.) Legr.

Psidium cf. nutans O. Berg.

morcego

pé-de-boi

sucupira

angiquinho

guaranazinho

fava-de-anta

cumbaru

carvão-vermelho

jatobá

barreiro

vinhático

pau-bosta

justa-conta

barbatimão

angelim

tarumã

$\begin{array}{lllll}1 & & & & 1 \\ & 2 & 2 & 1 & 2 \\ & & & & \\ & & & & \end{array}$

$\begin{array}{llll}2 & 2 & 2 & 2\end{array}$

2

1

1

1

6

66

1

1

12

$$
1
$$

1

1

12

$\begin{array}{lll}3 & 8 & 1\end{array}$

caneleira
quina

mangava-brava

1

sumanera

canjiqueira

paina

chico-magro

açoita-cavalo

embiruçu

manduvi

coroa-de-frade

cachuá

cabeludinho

balsemim

araçá

Myrtaceae 2

OLEACEAE

Linociera hassleriana (Chodat) Hassl.

OPILIACEAE

Agonandra brasiliensis Miers ex Benth. \& Hook. f.

RHAMNACEAE

Rhamnidium elaeocarpum Reiss.*

pau-de-vidro

tinge-cuia

cabrito
$4 \quad 1$

2

$\begin{array}{lll}3 & 3 \\ & 2 & 1 \\ & & \\ & & \\ & 1\end{array}$

$\begin{array}{llllll} & 1 & 4 & 1 & & 1 \\ 3 & 2 & 2 & 1 & 3 & \\ & & & 3 & & \end{array}$

$\begin{array}{lllll}1 & 3 & 3 & 5 & 7\end{array}$

2

1 
continuação

\begin{tabular}{|c|c|c|c|c|c|c|c|}
\hline \multirow[t]{2}{*}{ Família/ Espécie } & \multirow[t]{2}{*}{ Nome popular } & \multicolumn{6}{|c|}{ Áreas amostradas } \\
\hline & & 1 & 2 & 3 & 4 & 5 & 6 \\
\hline \multicolumn{8}{|l|}{ RUBIACEAE } \\
\hline Alibertia sessilis (Vell.) K. Schum. & marmelada & 1 & 15 & & 3 & & 6 \\
\hline Chomelia obtusa Cham. \& Schltdl. & espinheiro & 4 & 4 & & & & 3 \\
\hline cf. Rudgea sp. & & 1 & & & & & \\
\hline Tocoyena formosa (Cham. \& Schltdl.) K. Schum. & olho-de-boi & & 1 & & & & \\
\hline \multicolumn{8}{|l|}{ RUTACEAE } \\
\hline Zanthoxylum rigidum Humb. \& Bonpl. ex Willd. & maminha & 2 & 11 & & & & \\
\hline Z. naranjillo Griseb. & & & 2 & & & & \\
\hline Z. riedelianum Engl.* & & 1 & & & & & \\
\hline \multicolumn{8}{|l|}{ SALICACEAE } \\
\hline Casearia sylvestris Sw. & chá-de-frade & 4 & & & & & 4 \\
\hline \multicolumn{8}{|l|}{ SAPINDACEAE } \\
\hline Dilodendron bipinnatum Radlk.* & maria-pobre & & & & 2 & & 4 \\
\hline Magonia pubescens A. St.-Hil.* & timbó & & & 8 & 38 & 1 & 11 \\
\hline \multicolumn{8}{|l|}{ SAPOTACEAE } \\
\hline Chrysophyllum marginatum (Hook. \& Arn.) Radlk. & leiterinho & & 4 & & 2 & & 2 \\
\hline Pouteria cf. gardneri (Mart. \& Miq) Baehni* & & & 2 & & & & 4 \\
\hline Pouteria ramiflora (Mart.) Radlk & fruta-de-veado & 2 & 2 & & & 1 & 1 \\
\hline \multicolumn{8}{|l|}{ SIMAROUBACEAE } \\
\hline Simarouba versicolor A. St.-Hil. & perdiz & 1 & & & & 3 & \\
\hline \multicolumn{8}{|l|}{ VERBENACEAE } \\
\hline Aegiphila candelabrum Briq. ex Chodat \& Hassl. & & 1 & & & & & \\
\hline \multicolumn{8}{|l|}{ URTICACEAE } \\
\hline Cecropia pachystachya Trécul & embaúba & 11 & & & & & \\
\hline \multicolumn{8}{|l|}{ VOCHYSIACEAE } \\
\hline Qualea grandiflora Mart. & pau-terra-macho & & 1 & 14 & 12 & 3 & \\
\hline Q. parviflora Mart. & pau-terra & & & 3 & 1 & 3 & \\
\hline Salvertia convallariodora A. St.-Hil. & & & & 2 & & & \\
\hline Vochysia cinnamomea Pohl & quina-doce & & & & & 1 & \\
\hline
\end{tabular}

*espécies indicadoras de solos eutróficos.

apresentarem os solos mais diferentes em relação a fertilidade (V) e saturação por presença de alumínio (m) (figura 4).

As áreas com as maiores diversidades foram Nhumirim (3,36) e Imaculada $(3,22)$, ambas com elevado número de espécies (43 e 34, respectivamente) e eqüidade de aproximadamente 0,90 . Por outro lado, os cerradões Zequinha e Rio Negro foram os que apresentaram as menores diversidades (2,90 e 2,91). Apesar do elevado número de espécies do primeiro (37), a abundância predominante de duas espécies, Magonia pubescens e Qualea grandiflora, contribuíram para um valor mais baixo de eqüidade $(J=0,80)$. Na área do Rio Negro, o menor número de espécies, 27 apenas, deve ter influenciado o valor da diversidade já que a eqüidade, comparativamente, foi de 0,88 .
Solos - Os solos estudados apresentaram fertilidade variável entre si, corroborando os relatos de Ratter et al. (1988b), que verificaram que a vegetação arbórea no Pantanal ocorre de maneira descontínua, sobre cordilheiras (paleodiques aluviais), podendo-se encontrar cordilheiras próximas apresentando solos com fertilidades diferentes.

Considerando a saturação por bases (V) como indicador da fertilidade do solo, que representa a porcentagem da somatória de $\mathrm{K}$, Ca e Mg do solo em relação à capacidade de troca de cátions (CTC), pode-se classificar o cerradão Nhumirim como o de solo mais pobre, com V de 18\%; Capivari, Imaculada, Rio Negro e Zequinha podem ser considerados solos com fertilidade intermediária, com V variando de 25\% a $38 \%$, e Caron como o solo mais fértil, com V de 
50\% (tabela 3). Portanto, o cerradão Caron foi o único que apresentou solo eutrófico, com saturação por bases (V) de 50\% (sensu Reatto et al. 1998). Os outros cerradões apresentaram solos distróficos. Porém, segundo Ratter et al. (1978) todos esses solos seriam considerados distróficos, devido às baixas quantidades de cálcio trocável, inferior a 2,0 meq $100 \mathrm{~g}^{-1}$ $\left(=20 \mathrm{mmol}_{\mathrm{c}} \mathrm{dm}^{-3}\right)$.

O valor de saturação por alumínio (m), que representa a porcentagem de alumínio da somatória $\mathrm{K}$, $\mathrm{Ca}, \mathrm{Mg}$ e Al do solo, remetem para a mesma classificação

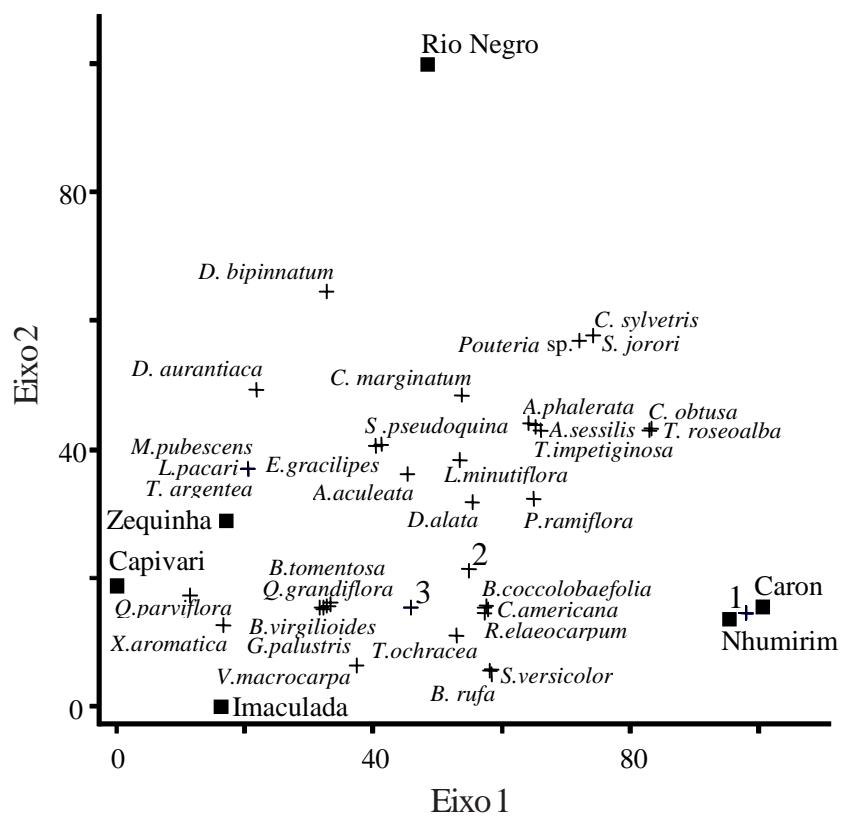

Figura 2. Ordenação pela análise de componentes principais (PCA) dos seis cerradões do Pantanal da Nhecolândia, Brasil, baseada na presença/ausência de 49 espécies. Primeiro eixo com 32\% de variância e autovalor de 15,7; segundo eixo com $26 \%$ de variância e autovalor de 12,8 . Nos números, em negrito, constam as seguintes espécies: $1+A$. brasiliensis, C. peruvianus, C. grandiflora, O. diospyrifolia, S. haematospermum e Z. rigidum; 2+ C. brasiliense, C. martii, D. furfuracea, D. hispida, D. mollis e S. obovatum; 3+ $H$. stigonocarpa, L. octandra, L. paniculata e M. elliptica. Os nomes completos das espécies estão na tabela 2.

Figure 2. Principal component analysis ordination of six savanna forests from "Pantanal da Nhecolândia" wetland, Brazil, based on presence and absence of 49 species. First axis with $32 \%$ of variance and eigenvalue of 15.7 ; second axis with $26 \%$ of variance and eigenvalue of 12.8 . The number in bold represent the following species: 1+ A. brasiliensis, C. peruvianus, C. grandiflora, O. diospyrifolia, $S$. haematospermum e Z. rigidum; $2+C$. brasiliense, C. martii, D. furfuracea, D. hispida, D. mollis e S. obovatum; 3+ H. stigonocarpa, L. octandra, L. paniculata, and M. elliptica. The complete names of the species are in table 2 .

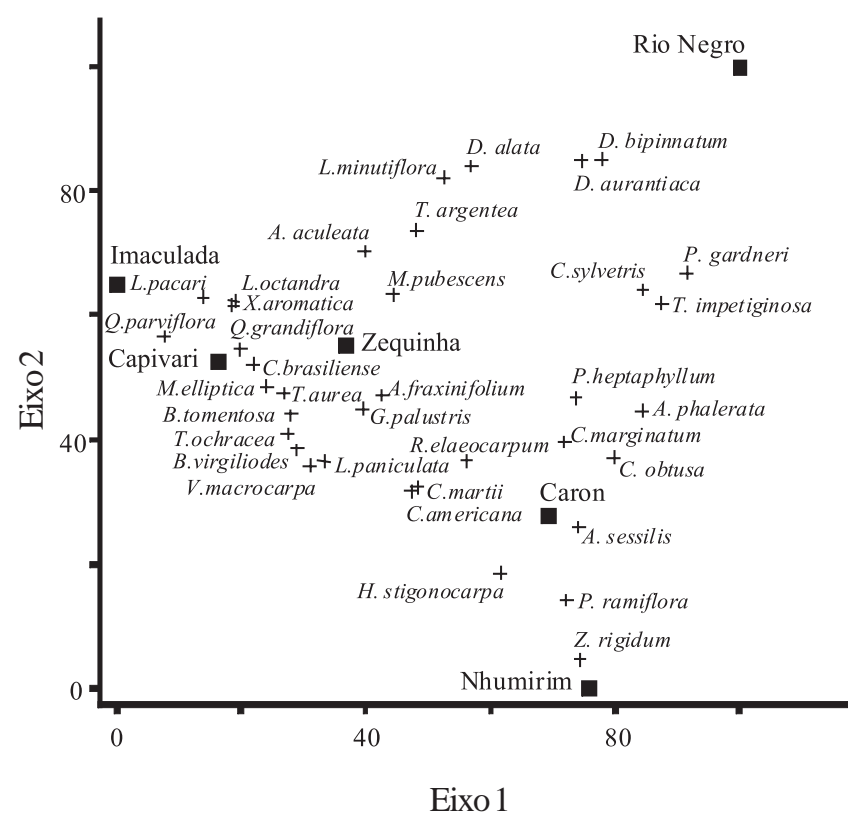

Figura 3. Ordenação pela análise de componentes principais (PCA) dos seis cerradões do Pantanal da Nhecolândia, Brasil, baseada na distribuição das 36 espécies mais abundantes. Os nomes completos das espécies constam na tabela 2 . Primeiro eixo com 33\% de variância e autovalor de 11,9; segundo eixo com 23\% de variância e autovalor de 8,1.

Figure 3. Principal component analysis ordination of six savanna forests from "Pantanal da Nhecolândia” wetland, Brazil, based on 36 most abundant species. The complete names of the species are in table 2. First axis with 33\% of variance and eigenvalue of 11.9 ; second axis with $23 \%$ of variance and eigenvalue of 8.1 .

de fertilidade do solo em relação ao $\mathrm{V}$, uma vez que valores mais elevados de $m$ representam solos de menor fertilidade. $\mathrm{O}$ valor de $\mathrm{m}$ foi elevado para o cerradão Nhumirim (47\%), intermediário para Capivari, Imaculada, Rio Negro e Zequinha (9,1\% a 31,8\%) e baixo para Caron (2,9\%). A soma de bases (SB), K + $\mathrm{Ca}+\mathrm{Mg}$, também refletiu a mesma tendência anterior, com valor mais elevado para Caron (17), baixo para Nhumirim $(3,9)$ e intermediário para os demais solos, 7,3 a $12,2 \mathrm{mmol}_{\mathrm{c}} \mathrm{dm}^{-3}$. ACTC foi semelhante para todos os solos, uma vez que os teores de matéria orgânica e argila são semelhantes. Quanto aos teores de fósforo, destaca-se o baixo teor para o cerradão Nhumirim ( $2 \mathrm{mg} \mathrm{dm}^{-3}$ ) e os mais elevados para os cerradões Capivari e Zequinha $\left(9 \mathrm{mg} \mathrm{dm}^{-3}\right)$. Na PCA para solos (figura 4), obteve-se no primeiro eixo um gradiente de fertilidade (V), que explicou 59\% da variância, com um autovalor de 10,7 . No segundo eixo (variância de $22 \%$ e autovalor de 3,9), entre os cerradões com solos de fertilidade intermediária, Capivari e Zequinha, tenderam 


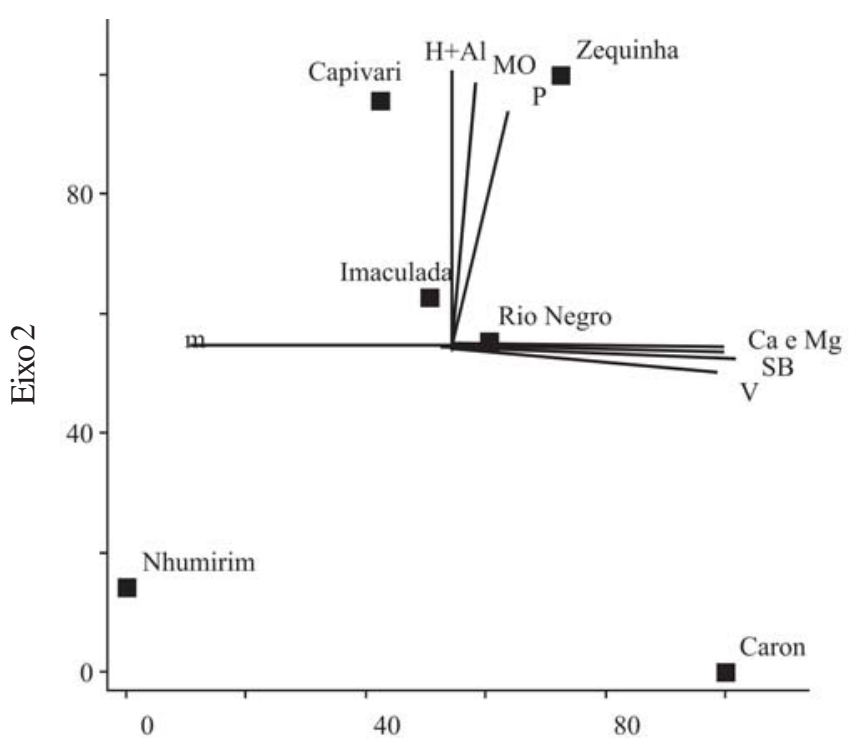

Eixo 1

Figura 4. Ordenação pela análise de componentes principais (PCA) dos seis cerradões do Pantanal da Nhecolândia, Brasil, baseada em 18 variáveis de solo, com representação gráfica de oito variáveis $(\mathrm{H}+\mathrm{Al}=$ hidrogênio mais alumínio; $\mathrm{Ca}=$ cálcio; $\mathrm{P}=$ fósforo; $\mathrm{Mg}=$ magnésio; $\mathrm{MO}=$ matéria orgânica; SB = soma de bases; $\mathrm{m}$ = saturação por alumínio e $\mathrm{V}=$ saturação por bases). Primeiro eixo com $59 \%$ de variância e autovalor de 10,7; segundo eixo com $22 \%$ de variância e autovalor de 3,9.

Figure 4. Principal component analysis ordination of six savanna forests from "Pantanal da Nhecolândia" wetland, Brazil, based on 18 soils variables. Eight variables were represented graphically $(\mathrm{H}+\mathrm{Al}=$ hydrogen plus aluminium; $\mathrm{Ca}=$ calcium; $\mathrm{P}=$ phosphorus; $\mathrm{Mg}=$ magnesium; $\mathrm{MO}=$ organic matter; SB = base sum; $\mathrm{m}$ = aluminium saturation and $\mathrm{V}=$ base saturation). First axis with $59 \%$ of variance and eigenvalue of 10.7; second axis with $22 \%$ of variance and eigenvalue of 3.9.

a formar um grupo, por apresentarem maiores teores de fósforo. Já Nhumirim e Caron, com fertilidades opostas no primeiro eixo, se agruparam no segundo, por apresentarem menores teores de matéria orgânica e fósforo.

O número de espécies e de indivíduos indicadores de solo eutrófico (tabelas 1,2 ) tende a aumentar no sentido da fertilidade do solo (tabela 3), exceto para o cerradão Caron, que apresentou número de espécies indicadoras similar ao dos cerradões com fertilidade intermediária.

Os cerradões Zequinha e Rio Negro, que ocorreram em solos distróficos com valores de fertilidade intermediários (V de 34\% e 38\%), apresentaram as maiores densidades de indivíduos de espécies indicadoras de solos eutróficos, com destaque para Magonia pubescens (tabelas 1-2).

O solo do cerradão Nhumirim foi o menos fértil $(\mathrm{V}=18 \%)$ e apresentou uma saturação por alumínio de $47 \%$, valor próximo ao limite para um solo ser considerado álico (sensu Reatto et al. 1998). Neste cerradão, observaram-se poucas árvores de espécies indicadoras de solos eutróficos (tabela 1).

\section{Discussão}

Comparando-se o número de espécies amostradas nos seis cerradões estudados com os obtidos por outros autores em cerradões (entre 25 e 43 espécies) nos Estados de Mato Grosso (Ratter et al. 1973 e Cunha \& Junk 1999), Mato Grosso do Sul (Ratter et al. 1988b e Dubs 1992) e São Paulo (Ratter et al. 1988a) os valores são parecidos. No entanto, cabe a ressalva de que os critérios de amostragem utilizados nesses trabalhos são apenas semelhantes, não sendo exatamente os mesmos. Esses valores são inferiores quando comparados aos obtidos por Ratter et al. (1977) em cerradão no Vale dos Sonhos (67 espécies) no Estado do Mato Grosso e por Ratter (1987) em cerradões no Parque Nacional do Araguaia (58 a 64 espécies) no Estado de Tocantins. Ratter et al. (1997) reportam que áreas de cerrado nos Estados do Mato Grosso (região do Alto Araguaia), Tocantins e Distrito Federal são as que apresentam maior número de espécies ("hotspots” de biodiversidade).

A riqueza de espécies observada nas áreas de cerradão da fazenda Rio Negro e Nhumirim confirma o observado por Eiten (1990), que cerradões muito fechados apresentam menor número de espécies do que cerradões mais abertos, devido ao sombreamento produzido pelo dossel que limitaria o crescimento das plantas na camada inferior, enquanto nos cerradões com dossel mais aberto, ocorre sub-bosque mais denso, com maior número de espécies por área.

A diversidade de espécies observada nos cerradões estudados ( $H^{\prime}$ entre 2,90 e 3,36) está próxima dos valores obtidos por Salis (2000) em outras áreas de cerradão na fazenda Nhumirim, Corumbá, Pantanal no Mato Grosso do Sul ( $H^{\prime}$ entre 2,87 e 3,02) e por Felfili \& Silva (1993) em áreas de cerrado em Paracatu e Silvânia no Estado de Minas Gerais ( $H^{\prime}=3,11$ e 3,31, respectivamente). Porém, são valores considerados baixos quando comparados com outras áreas de cerrado sensu stricto do Brasil Central estudadas por Felfili et al. (1997). De acordo com Oliveira Filho \& Ratter (2002), o número de espécies de árvores e arbustos que ocorrem 
Tabela 3. Variáveis de solo dos seis cerradões do Pantanal da Nhecolândia, Brasil. (V = saturação por bases; $m$ = saturação por alumínio; $\mathrm{MO}$ = matéria orgânica; $\mathrm{CTC}$ = capacidade de troca catiônica; $\mathrm{SB}$ = soma de bases, $\mathrm{Al}$ = alumínio; $\mathrm{H}+\mathrm{Al}$ = hidrogênio mais alumínio; $\mathrm{Ca}=$ cálcio, $\mathrm{Mg}$ = magnésio; $\mathrm{K}$ = potássio; $\mathrm{P}=$ fósforo; $\mathrm{S}=$ enxofre; $\mathrm{B}=$ boro; $\mathrm{Cu}$ = cobre; $\mathrm{Fe}=$ ferro, $\mathrm{Mn}=$ manganês; $\mathrm{Zn}=$ zinco).

Table 3. Soil variables from six savanna forests of "Pantanal da Nhecolândia" wetland, Brazil. ( $\mathrm{V}=$ bases saturation; $\mathrm{m}$ = aluminium saturation; $\mathrm{MO}$ = organic matter; $\mathrm{CTC}$ = exchangeable cations capacity; $\mathrm{SB}=$ sum of bases; $\mathrm{Al}=$ aluminium; $\mathrm{H}+\mathrm{Al}=$ hydrogen plus aluminium; $\mathrm{Ca}=$ calcium; $\mathrm{Mg}$ = magnesium; $\mathrm{K}$ = potassium; $\mathrm{P}=$ phosphorus; $\mathrm{S}$ = sulphur; $\mathrm{B}=$ boron; $\mathrm{Cu}=$ copper; $\mathrm{Fe}=$ iron; $\mathrm{Mn}=$ manganese; $\mathrm{Zn}=$ zinc).

\begin{tabular}{|c|c|c|c|c|c|c|}
\hline & Caron & Nhumirim & Capivari & Zequinha & Imaculada & Rio Negro \\
\hline $\mathrm{pH}$ em $\mathrm{CaCl}_{2}$ & 4,7 & 4,0 & 4,1 & 4,4 & 4,1 & 4,5 \\
\hline $\mathrm{V}(\%)$ & 50,0 & 18,0 & 25,0 & 34,0 & 29,0 & 38,0 \\
\hline m(\%) & 2,9 & 47,3 & 31,8 & 15,9 & 16,7 & 9,1 \\
\hline $\mathrm{MO}\left(\mathrm{g} \mathrm{dm}^{-3}\right)$ & 11,0 & 10,0 & 14,0 & 14,0 & 13,0 & 13,0 \\
\hline CTC $\left(\mathrm{mmol}_{\mathrm{c}} \mathrm{dm}^{-3}\right)$ & 34,0 & 21,9 & 29,3 & 36,2 & 31,0 & 32,0 \\
\hline $\mathrm{SB}\left(\mathrm{mmol}_{\mathrm{c}} \mathrm{dm}^{-3}\right)$ & 17,0 & 3,9 & 7,3 & 12,2 & 9,0 & 12,0 \\
\hline $\mathrm{Al}\left(\mathrm{mmol}_{\mathrm{c}} \mathrm{dm}^{-3}\right)$ & 0,5 & 3,5 & 3,4 & 2,3 & 1,8 & 1,2 \\
\hline $\mathrm{H}+\mathrm{Al}\left(\mathrm{mmol}_{\mathrm{c}} \mathrm{dm}^{-3}\right)$ & 17,0 & 18,0 & 22,0 & 24,0 & 22,0 & 20,0 \\
\hline $\mathrm{Ca}\left(\mathrm{mmol}_{\mathrm{c}} \mathrm{dm}^{-3}\right)$ & 10,0 & 2,0 & 4,0 & 7,0 & 6,0 & 8,0 \\
\hline $\mathrm{Mg}\left(\mathrm{mmol}_{\mathrm{c}} \mathrm{dm}^{-3}\right)$ & 5,0 & 1,0 & 2,0 & 4,0 & 2,0 & 3,0 \\
\hline $\mathrm{K}\left(\mathrm{mmol}_{\mathrm{c}} \mathrm{dm}^{-3}\right)$ & 2,0 & 0,9 & 1,3 & 1,2 & 1,0 & 1,0 \\
\hline $\mathrm{P}\left(\mathrm{mg} \mathrm{dm}^{-3}\right)$ & 5,0 & 2,0 & 9,0 & 9,0 & 7,0 & 7,0 \\
\hline $\mathrm{S}\left(\mathrm{mg} \mathrm{dm}^{-3}\right)$ & 6,0 & 5,0 & 4,0 & 4,0 & 6,0 & 4,0 \\
\hline $\mathrm{B}\left(\mathrm{mg} \mathrm{dm} \mathrm{dm}^{-3}\right)$ & 0,2 & 0,1 & 0,2 & 0,1 & 0,1 & 0,1 \\
\hline $\mathrm{Cu}\left(\mathrm{mg} \mathrm{dm}^{-3}\right)$ & 0,5 & 0,4 & 0,5 & 0,5 & 0,3 & 0,4 \\
\hline $\mathrm{Fe}\left(\mathrm{mg} \mathrm{dm}^{-3}\right)$ & 47,0 & 99,0 & 50,0 & 47,0 & 65,0 & 66,0 \\
\hline $\operatorname{Mn}\left(\mathrm{mg} \mathrm{dm}^{-3}\right)$ & 30,0 & 8,6 & 17,3 & 20,5 & 25,0 & 19,2 \\
\hline $\mathrm{Zn}\left(\mathrm{mg} \mathrm{dm}^{-3}\right)$ & 0,5 & 0,2 & 0,4 & 0,7 & 0,5 & 0,4 \\
\hline
\end{tabular}

num único local de cerrado pode chegar a 150 por hectare, mas geralmente, é inferior, principalmente nos cerradões sobre solos eutróficos com dominância de espécies indicadoras desses solos, como Callisthene fasciculata Mart., Magonia pubescens, Terminalia argentea e Luehea paniculata.

Das 86 espécies encontradas, considerando-se as seis áreas de estudo conjuntamente, 34 espécies (cerca de $40 \%$ do total) ocorreram em apenas uma das áreas. Heterogeneidade semelhante foi observada por Ratter et al. (2003) em uma escala maior, onde, das 951 espécies anotadas em 376 áreas de cerrado comparadas, 334 (35\%) ocorreram em apenas um local.

Os cerradões Caron e Nhumirim foram os mais similares na composição florística e na estrutura (abundância das espécies), apesar de apresentarem os solos mais diferentes em relação a fertilidade. Esperava-se que a composição florística fosse diferente, conforme observaram Goodland \& Pollard (1973) e Ratter et al. (1977) em cerradões de Minas Gerais, Mato Grosso e Goiás, onde a heterogeneidade florística e estrutural estava relacionada aos diferentes níveis de fertilidade do solo. No entanto, esses dois cerradões apresentaram várias espécies em comum e que não ocorreram nas outras áreas, como Agonandra brasiliensis, Couepia grandiflora, Ocotea diospyrifolia, Sapium haematospermum, Cereus peruvianus e Zanthoxylum rigidum (= Fagara hassleriana), as duas últimas muito freqüentes em locais mais abertos no Pantanal (Ratter et al. 1988b). A presença das espécies de locais abertos nessas duas áreas ocorreu por motivos diferentes. No cerradão Caron, a vegetação estaria em um processo de regeneração, devido ao histórico de retirada de madeira. A ocorrência de muitas árvores de Cecropia pachystachya, a terceira espécie mais densa no interior do cerradão Caron, confirma a alteração sofrida e a regeneração. No caso de Nhumirim, o cerradão apresentaria originalmente dossel mais aberto, com poucas árvores de grande porte e muitas árvores de menor porte, por causa da menor fertilidade do solo e da elevada saturação por alumínio. A mesma variação 
de porte em relação à fertilidade foi observada por Goodland \& Pollard (1973) e Eiten (1990) em outras áreas de cerrado. Estruturalmente, Nhumirim e Caron apresentaram, em comum, muitos indivíduos de Protium heptaphyllum e ausência de árvores, como Magonia pubescens e Lafoensia pacari, que ocorreram com abundância em alguns dos cerradões estudados.

As áreas Caron, Capivari, Imaculada e Zequinha apresentaram predomínio de espécies comuns em cerradão no Pantanal, mencionadas por Ratter et al. (1988b), como Acrocomia aculeata, Astronium fraxinifolium, Dipteryx alata, Luehea paniculata, Magonia pubescens, Terminalia argentea e Vatairea macrocarpa. Nos cerradões Capivari e Zequinha foram observados, ainda, muitos indivíduos de Qualea grandiflora, espécie muito freqüente nas áreas de cerrado, sendo a única que Ratter et al. $(1996,2003)$ encontraram ocorrendo em $82 \%$ e $85 \%$, respectivamente, dos cerrados comparados.

Os cerradões que apresentam muitos indivíduos de Qualea spp. foram descritos e denominados por Ratter et al. (1973) como cerradões indiferenciados em relação à fertilidade do solo. Segundo os autores, é um tipo de cerradão que ocorre por todo o domínio do cerrado, com uma composição de espécies mais ou menos parecida com o cerrado aberto, diferindo apenas na maior altura e densidade das árvores. De acordo com Ratter et al. (1973), sua ocorrência estaria associada a locais com melhor suprimento de água ou com outro fator edáfico importante para o crescimento das árvores. Outros autores como Ribeiro et al. (1985), Oliveira Filho et al. (1989), Nascimento \& Saddi (1992) e Cardoso \& Schiavini (2002) também apontam para a relação entre a ocorrência de Qualea e algum fator edáfico, sem, entretanto, identificá-lo. Moffat (1971), apud Ratter et al. (1973), sugere que a disponibilidade de fósforo (P) possa ser esse fator, e os dados obtidos nos cerradões Capivari e Zequinha, nos quais há maior disponibilidade de P e muitos indivíduos de Qualea grandiflora, parece concordar com essa explicação. Ratter et al. (1973) consideraram Qualea grandiflora uma espécie indiferente às condições edáficas, ocorrendo tanto em solos eutróficos quanto distróficos, independentemente dos teores de Ca e Mg no solo. De fato, a espécie parece ser indiferente aos teores de $\mathrm{Ca}$ e $\mathrm{Mg}$ no solo, mas provavelmente não é indiferente ao maior teor de $\mathrm{P}$, macro-nutriente que a planta acumula em suas sementes junto com o Al (Felippe 1990). Uma concentração excessiva de $\mathrm{Al}$ no solo pode reduzir a absorção de $\mathrm{P}$ (Goodland 1979), mas a toxidez do Al diminui quando o fosfato está presente em concentração equivalente
(McLean \& Gilbert 1928, apud Goodland 1979). Talvez esta seja a razão para Qualea grandiflora ter sido mais abundante em solos com maiores teores de P. O teor de $P$ no solo inferior a $5 \mathrm{mg} \mathrm{dm}^{-3}$ é considerado baixo para árvores nativas de Mata Atlântica, enquanto que valores de 6 a $12 \mathrm{mg} \mathrm{dm}^{-3}$ são considerados médios (Gonçalves et al. 1997). Nos cerradões Capivari, Zequinha e Imaculada, com maior ocorrência de Qualea grandiflora, foram observados entre 7 a $9 \mathrm{mg} \mathrm{dm}^{-3} \mathrm{de}$ $\mathrm{P}$ no solo. A quantidade de $\mathrm{P}$ encontrada por Felippe (1990) nos solos distróficos do cerrado de Itirapina, onde Qualea grandiflora é muito freqüente, foi de $6 \mathrm{mg} \mathrm{dm}^{-3}$, valor considerado médio (Gonçalves et al. 1997) e próximo ao observado nos cerradões com Q. grandiflora no Pantanal.

Não foi possível comparar os teores de nutrientes (Ca, P, etc.) aqui obtidos com outros trabalhos desenvolvidos em cerrado que relacionam vegetação com características edáficas, devido às diferentes metodologias utilizadas na coleta, análise e apresentação dos resultados. Torna-se necessária a uniformização dos métodos empregados para viabilizar as comparações entre os trabalhos, como demonstrado por Ratter et al. (1977) e Nascimento \& Saddi (1992). Esses autores compararam diferentes áreas de cerrado empregando os mesmos procedimentos de análise de solos, calculando-se a proporção de Ca em relação ao P para cada área. Nas áreas que ocorreram Qualea grandiflora em abundância, os teores de $\mathrm{P}$ em relação ao Ca foram maiores, enquanto que nas áreas sem a espécie a quantidade de $\mathrm{P}$ em relação ao $\mathrm{Ca}$ foi menor. Cada espécie vegetal tem um requerimento de nutrientes e uma relação ideal entre os mesmos (Albrecht 1967) e, para Qualea grandiflora a maior proporção de P em relação ao Ca é importante. No caso, observou-se apenas a proporção entre o Ca e o $\mathrm{P}$, mas para que se possa compreender mais claramente a distribuição das espécies nativas no cerrado, deve-se estudar a proporção entre todos os nutrientes.

Segundo Ratter et al. (1973), Magonia pubescens é uma espécie indicadora de cerradão eutrófico, porém como explicar sua abundância num solo distrófico, como o cerradão Zequinha, com pouco Ca disponível? Ratter et al. (1977) afirmam que as espécies calcícolas têm seu habitat limitado por processos químicos mais sutis do que apenas a necessidade de Ca no solo, como por exemplo, a toxidez de Al (Goodland \& Pollard 1973). Assim, de acordo com Ratter et al. (1977), as espécies típicas de solos eutróficos estariam restritas ao habitat, possivelmente pela sensibilidade ao $\mathrm{Al}$ e não somente por efeito direto do Ca. Dentre os cerradões estudados 
com solos distróficos, Zequinha é um dos mais férteis, com $\mathrm{V}$ de $34 \%$, com pouco Ca e saturação por Al baixa $(\mathrm{m}=16 \%)$.

Goodland \& Pollard (1973) ressaltam a dificuldade de se determinar um agente único para cada característica observada na vegetação do cerrado. $\mathrm{O}$ fogo, por exemplo, além de afetar diretamente as plantas, pode acentuar ou diminuir diferenças de fertilidade do solo, pela volatilização do N e S (Goodland \& Pollard 1973) e pelo diferente tempo de retorno de cada nutriente ao ecossistema. Segundo Pivello \& Coutinho (1992), o P e o S são repostos, após a passagem do fogo, em menos de um ano; Ca, leva entre 1 e 3 anos; $\mathrm{K}$, entre 1,5 e 4 anos e Mg, de 1 a 5 anos. Assim, em uma área queimada regularmente a cada dois anos supõe-se que o $\mathrm{P}$ e o $\mathrm{S}$ teriam seus teores acrescidos no solo, enquanto que o Ca e o $\mathrm{Mg}$ tenderiam a diminuir. Esta alteração na disponibilidade dos nutrientes poderia, por exemplo, estar favorecendo o estabelecimento de Qualea grandiflora no cerradão Zequinha.

A distribuição das espécies nos cerradões das cordilheiras do Pantanal não está condicionada somente às características de solo e clima, mas também provavelmente às ações antrópicas de retirada de madeira, desmatamento (Silva et al. 1999), presença de gado (Soares 1997, Johnson et al. 1997) e fogo, que em curto ou longo prazo podem descaracterizar esta fisionomia na planície pantaneira.

Agradecimentos - Aos proprietários, Sr. José de Barros (fazenda Campo Alto), Senhora Ivy Barros (fazenda Imaculada), Sr. Abílio Leite de Barros (fazenda Rancharia) e à Conservação Internacional do Brasil (fazenda Rio Negro), pela pronta acolhida nas coletas de campo. À Embrapa, pela concessão da bolsa de doutorado. À Universidade Federal de São Carlos, Centro de Ciências Agrárias do campus de Araras, pelas análises das amostras de solo. Aos doutores, James A. Ratter, botânico do Royal Botanic Garden de Edinburgh, Reinaldo Monteiro, professor da Unesp - Rio Claro, Guilherme Mourão, pesquisador da Embrapa Pantanal, pelas sugestões ao manuscrito. À Engenheira Agrônoma Charlotte Salis, pela introdução aos conceitos da Agroecologia. Aos colegas da Embrapa Pantanal, Oslain, Geraldo, Américo, Denis, Moacir e Antonio, pelo apoio imprescindível nas viagens de coleta e pelo acondicionamento do material coletado.

\section{Referências bibliográficas}

ALBRECHT, W.A. 1967. Soil reactions (pH) and balanced plant nutrition. http://www.soilandhealth.org/ 01aglibrary/010143albpap/pH.balanced\%20nutrition/ pH.bal.nut.html (acesso em 08/03/2004).
APG II (ANGIOSPERM PHYLOGENY GROUP). 2003. An update of the angiosperm phylogeny group classification for the orders and families of flowering plants: APG II. Botanical Journal of the Linnean Society 141:399-436.

BROWER, J.E. \& ZAR, J.H. 1984. Field and laboratory methods for general ecology. $2^{\text {nd }}$ ed., C. Brown, Iowa.

CARDOSO, E. \& SCHIAVINI, I. 2002. Relação entre distribuição de espécies arbóreas e topografia em um gradiente florestal na Estação Ecológica do Panga (Uberlândia, MG). Revista Brasileira de Botânica 25:277-289.

CASTRO, A.A.J.F., MARTINS, F.R., TAMASHIRO, J.Y. \& SHEPHERD, G.J. 1999. How rich is the flora of Brazilian cerradões? Annals of Missouri Botanical Garden 86:192-224.

CUNHA, N.G. 1980. Considerações sobre os solos da subregião da Nhecolândia, Pantanal Mato-grossense. Circular Técnica 1, Embrapa-UEPAE, Corumbá.

CUNHA, N.G. 1981. Classificação e fertilidade de solos da planície sedimentar do Rio Taquari, Pantanal Matogrossense. Circular Técnica 4, Embrapa-UEPAE, Corumbá.

CUNHA, N.G. 1985. Solos calcimórficos de Corumbá. Circular Técnica 18, Embrapa-CPAP, Corumbá.

CUNHA, C.N. 1990. Estudo florístico e fito-fisionômico das principais formações arbóreas do Pantanal de Poconé, Mato Grosso. Dissertação de mestrado, Universidade Estadual de Campinas, Campinas.

CUNHA, C.N. \& JUNK, W.J. 1999. Composição florística de capões e cordilheiras: localização das espécies lenhosas quanto ao gradiente de inundação no Pantanal de Poconé, MT - Brasil. In Anais do II Simpósio sobre Recursos Naturais e Sócio-econômicos do Pantanal (M. Dantas, J.B. Catto \& E.K. Resende, coords.). Embrapa Pantanal, Corumbá, p.387-405.

DAMASCENO JÚNIOR, G., BEZERRA, M.A.O., BORTOLOTTO, I.M. \& POTT, A. 1999. Aspectos florísticos e fito-fisionômicos dos capões do Pantanal do Abobral. In Anais do II Simpósio sobre Recursos Naturais e Sócio-econômicos do Pantanal (M. Dantas, J.B. Catto \& E.K. Resende, coords.). Embrapa Pantanal, Corumbá, p.204-214.

DUBS, B. 1992. Observations on the differentiation of woodland and wet savanna habitats in the Pantanal of Mato Grosso, Brazil. In Nature and dynamics of forestsavanna boundaries (P.A. Furley, J. Proctor \& J.A. Ratter, eds.). Chapman \& Hall, London, p.431-449.

EITEN, G. 1990. Vegetação do Cerrado. In Cerrado Caracterização, ocupação e perspectivas. (M.N. Pinto, org.). Editora Universidade de Brasília, Brasília, p.9-65.

EMBRAPA. 1997. Boletim Agrometeorológico: 1986-1996 (Fazenda Nhumirim). Boletim Agrometeorológico 3. Embrapa-CPAP, Corumbá.

EMBRAPA. 1999. Sistema brasileiro de classificação de solos. Empresa Brasileira de Pesquisa Agropecuária, Embrapa Solos, Rio de Janeiro \& Embrapa Produção de Informação, Brasília. 
FELFILI, J.M. \& SILVA JÚNIOR, M.C. 1993. A comparative study of cerrado (sensu stricto) vegetation in Central Brazil. Journal of Tropical Ecology 9:277-289.

FELFILI, J.M., SILVA JÚNIOR, M.C., REZENDE, A.V., NOGUEIRA, P.E., WALTER, B.M.T., FELFILI, M.C., SILVA, M.A. \& IMAÑA-ENCINAS, J. 1997. Comparação do cerrado (sensu stricto) nas Chapadas Pratinha e dos Veadeiros. In Contribuição ao conhecimento ecológico do Cerrado (L.L. Leite \& C.H. Saito, orgs.). Departamento de Ecologia, Universidade de Brasília, Brasília, p.6-11.

FELIPPE, G.M. 1990 Qualea grandiflora: the seed and its germination. Revista Brasileira de Botânica 13:33-37.

GONÇALVES, J.L.M., RAIJ, B. VAN \& GONÇALVES, J.C. 1997. Florestais. In Recomendações de adubação e calagem para o Estado de São Paulo. Boletim Técnico 100 (B. van Raij, H. Cantarella, J.A. Quaggio \& A.M.C. Furlani, eds.). Instituto Agronômico - Fundação IAC, Campinas, p.247-259.

GOODLAND, R. 1979. Análise ecológica da vegetação do cerrado. In Ecologia do cerrado (R. Goodland \& M.G. Ferri, eds.). Itatiaia Editora \& Editora da Universidade de São Paulo, Belo Horizonte \& São Paulo, p.61-160.

GOODLAND, R. \& POLLARD, R. 1973. The Brazilian cerrado vegetation: a fertility gradient. Journal of Ecology 61:219-224.

GUARIM NETO, G. 1991. Plantas do Brasil - Angiospermas do Estado de Mato Grosso - Pantanal. Acta Botanica Brasilica 5:25-47.

HAMILTON, S.K., SIPPEL, S.J. \& MELACK, J.M. 1996. Inundation patterns in the Pantanal wetland of South America determined from passive microwave remote sensing. Archives of Hydrobiology 137:1-23.

JOHNSON, M.A., TOMÁS, W.M. \& GUEDES, N.M.R. 1997. On the Hyacinth macaw's nesting tree: density of young manduvis around adult trees under three different management conditions in the Pantanal wetland, Brazil. Ararajuba 5:185-188.

KENT, M. \& COKER, P. 1999. Vegetation description and analysis: a practical approach. J. Wiley, London.

MALME, G.O.A.N. 1905. Die Vochysiaceen Matto Grosso. Arkiv för Botanik 5:1-12.

MCCUNE, B. \& MEFFORD, M.J. 1999. Multivariate analysis of ecological data - PC-ORD version 4.14, Users guide. MjM Software Design, Gleneden Beach.

MOORE, S.M. 1895. The phanerogamic botany of the Mato Grosso expedition 1891-1892. Transactions of the Linnean Society of London. Series Botany 4:265-516.

NASCIMENTO, M.T. \& CUNHA, C.N. 1989. Estrutura e composição florística de um cambarazal no Pantanal de Poconé, MT. Acta Botanica Brasilica 3:3-23.

NASCIMENTO, M.T. \& SADDI, N. 1992. Structure and floristic composition in an area of cerrado in CuiabáMT, Brazil. Revista Brasileira de Botânica 15:47-55.

OLIVEIRA FILHO, A.T. \& RATTER, J.A. 1995. A study of the origin of central Brazilian forests by the analysis of plant species distributions patterns. Edinburgh Journal of Botany 52:141-194.
OLIVEIRA FILHO, A.T. \& RATTER, J.A. 2002. Vegetation physiognomies and woody flora of the Cerrado Biome. In The cerradões of Brazil: ecology and natural history of Neotropical savanna. (P.S. Oliveira \& R.J. Marquis, eds.). Columbia University Press, New York, p.91-120.

OLIVEIRA FILHO, A.T., SHEPHERD, G.J. MARTINS, F.R. \& STUBBLEBINE, W.H. 1989. Environmental factors affecting physiognomic and floristic variations in an area of cerrado in Central Brazil. Journal of Tropical Ecology 5:413-431.

PIVELLO, V.R. \& COUTINHO, L.M. 1992. Transfer of macronutrients to the atmosphere during experimental burnings in an open cerrado (Brazilian savanna). Journal of Tropical Ecology 8:487-497.

POTT, A., POTT, V.J., RATTER, J.A. \& VALLS, J.F.M. 1986. Flora da fazenda Nhumirim, Nhecolândia, Pantanal: relação preliminar. Pesquisa em Andamento 5. Embrapa - CPAP, Corumbá.

POTT, A., SILVA, J.S.V., ABDON, M.M., POTT, V.J., RODRIGUES, L.M., SALIS, S.M. \& HATSCHBACH, G.G. 1997. Vegetação. In Brasil. Ministério do Meio Ambiente, dos Recursos Hídricos e da Amazônia Legal. Plano de conservação da bacia do alto Paraguai (Pantanal) - PCBAP. Diagnóstico dos meios físico e biótico: meio biótico. MMA/ SEMAM/ PNMA, Brasília, v.2, p.3-179.

PRADO, D.E. \& GIBBS, P.E. 1993. Patterns of species distributions in the dry seasonal forests of South America. Annals of Missouri Botanical Garden 80: 902-927.

PRANCE, G.T. \& SCHALLER, G.B. 1982. Preliminary study of some vegetation types of the Pantanal, Mato Grosso, Brazil. Brittonia 34:228-251.

RAIJ, B. VAN, QUAGGIO, J.A., CANTARELLA, H., FERREIRA, M.E., LOPES, A.S. \& BATAGLIA, O.C. 1987. Análise química de solo para fins de fertilidade. Fundação Cargill, Campinas.

RATTER, J.A. 1987. Notes on the vegetation of the Parque Nacional do Araguaia (Brazil). Notes from the Royal Botanic Garden Edinburgh 44:311-342.

RATTER, J.A., RICHARDS, P.W., ARGENT, G. \& GIFFORD, D.R. 1973. Observations on the vegetation of northeastern Mato Grosso, I. The woody vegetation types of the Xavantina-Cachimbo Expedition area. Philosophical Transactions of the Royal Society of London 226:449-492.

RATTER, J.A., ASKEW, G.P., MONTGOMERY, R.F. \& GIFFORD, D.R. 1977. Observações adicionais sobre o cerradão de solos mesotróficos no Brasil Central. In IV Simpósio sobre o cerrado (M.G. Ferri, ed.). Universidade de São Paulo, São Paulo, p.306-316. 
RATTER, J.A., ASKEW, G.P., MONTGOMERY, R.F. \& GIFFORD, D.R. 1978. Observations on forests of some mesotrophic soils in Central Brazil. Revista Brasileira de Botânica 1:47-58.

RATTER, J.A., LEITÃO FILHO, H.F., ARGENT, G., GIBBS, P.E., SEMIR, J., SHEPHERD, G. \& TAMASHIRO, J. 1988a. Floristic composition and community structure of a southern cerrado area in Brazil. Notes from the Royal Botanic Garden Edinburgh 45:137-151.

RATTER, J.A., POTT, A., POTT, V.J., CUNHA, C.N. \& HARIDASSAN, M. 1988b. Observations on woody vegetation types in the Pantanal and around Corumbá. Notes from the Royal Botanic Garden Edinburgh 45:503-525.

RATTER, J.A., BRIDGEWATER, S., ATKINSON, R. \& RIBEIRO, J.F. 1996. Analysis of the floristic composition of the Brazilian cerrado vegetation II: comparison of the woody vegetation of 98 areas. Edinburgh Journal Botany 53:153-180.

RATTER, J.A., RIBEIRO, J.F. \& BRIDGEWATER, S. 1997. The Brazilian cerrado vegetation and threats to its biodiversity. Annals of Botany 80:223-230.

RATTER, J.A., BRIDGEWATER, J.F. \& RIBEIRO, J.F. 2003. Analysis of the floristic composition of the Brazilian cerrado vegetation III: comparison of the woody vegetation of 376 areas. Edinburgh Journal Botany 60:57-109.

REATTO, A., CORREIA, J.R. \& SPERA, S.T. 1998. Solos do bioma cerrado: aspectos pedológicos. In Cerrado: ambiente e flora (S.M. Sano \& S.P. Almeida, eds.). Embrapa CPAC, Planaltina, p.47-86.

RIBEIRO, J.F., SILVA, J.C.S. \& BATMANIAN, G.J. 1985. Fitossociologia de tipos fisionômicos de cerrado em Planaltina-DF. Revista Brasileira de Botânica. 8:131-142.

SALIS, S.M. 2000. Fitossociologia da vegetação arbórea no entorno de uma lagoa no Pantanal Mato-Grossense, Brasil. Naturalia 25:225-241.
SALIS, S.M., POTT, V.J. \& POTT, A. 1999. Fitossociologia de formações arbóreas da bacia do alto Paraguai. In Anais do II Simpósio sobre Recursos Naturais e Sócioeconômicos do Pantanal (M. Dantas, J.B. Catto \& E.K. Resende, coords.). Embrapa Pantanal, Corumbá, p.357-374.

SANTOS, R.D., CARVALHO FILHO, A., NAIME, U.J., OLIVEIRA, H., MOTTA, P.E.F., BARUQUI, A.M., BARRERO, W.O., MELO, M.E.C.C.M., PAULA, J.L., SANTOS, E.M.R. \& DUARTE, M.N. 1997. Pedologia. In Brasil. Ministério do Meio Ambiente, dos Recursos Hídricos e da Amazônia Legal. Plano de conservação da bacia do alto Paraguai (Pantanal) - PCBAP. Diagnóstico dos meios físico e biótico: meio físico. MMA/ SEMAM/ PNMA, Brasília, v.2, p.120-293.

SHEPHERD, G.J. 1988. FITOPAC 1. Manual do usuário. Departamento de Botânica, Instituto de Biologia, Universidade Estadual de Campinas, Campinas.

SILVA, M.P., MAURO, R., MOURÃO, G. \& COUTINHO, M. 1999. Conversion of forests and woodlands to cultivated pastures in the wetland of Brazil. Ecotropicos 12:101-108.

SOARES, C.R.A. 1997. Estrutura e composição florística de duas comunidades vegetais sob diferentes condições de manejo, Pantanal da Nhecolândia, MS. Tese de mestrado, Universidade Federal do Mato Grosso, Cuiabá.

SORIANO, B.M.A. 1999. Caracterização climática da subregião da Nhecolândia, Pantanal, MS. In Anais do II Simpósio sobre recursos naturais e sócio-econômicos do Pantanal (M. Dantas, J.B. Catto \& E.K. Resende, coords.). Embrapa Pantanal, Corumbá, p.151-158.

SORIANO, B.M.A. 2002. Boletim Agrometeorológico: 1999 (Fazenda Nhumirim). Documentos 26. Embrapa Pantanal, Corumbá.

VELOSO, H.P. 1947. Considerações gerais sobre a vegetação do Estado do Mato Grosso II. Notas preliminares sobre o Pantanal e zonas de transição. Memórias do Instituto Oswaldo Cruz 45:253-272. 